\title{
Cerebral arteriovenous malformations: influence of angioarchitecture on bleeding risk
}

\author{
R. Kubalek ${ }^{1}$, A. Moghtaderi ${ }^{2}$, J. Klisch ${ }^{1}$, A. Berlis ${ }^{1}$, A. Quiske $^{3}$, and M. Schumacher \\ ${ }^{1}$ Department of Neuroradiology, University of Freiburg, Freiburg, Germany \\ ${ }^{2}$ Department of Neurology, Zahedan University School of Medical Sciences, Zahedan, Iran \\ ${ }^{3}$ Department of Neurosurgery, University of Freiburg, Freiburg, Germany
}

\section{Summary}

Background. To evaluate the angioarchitecture of cerebral arteriovenous malformations (cAVMs) with special regard to its influence on the risk of intracranial haemorrhage.

Methods. Clinical and neuroradiological data of 171 patients with cAVMs, who were treated at our department, were analysed retrospectively. The angioarchitectonic data were obtained from angiographic series, cranial CT scans and MR images. A $\chi^{2}$ test was conducted to correlate the parameters and determine the $P$ values.

Findings. The following parameters correlate to an increased risk of haemorrhage: diameter of the nidus $\leq 2 \mathrm{~cm}(P<0.001)$, number of arterial feeders $\leq 2(P<0.001)$, diameter of the main feeder $\leq 1 \mathrm{~mm}$ $(P<0.0001)$, number of veins draining the nidus $\leq 2(P<0.001)$, exclusive deep drainage $(P<0.05)$, and low or middle flow-velocity $(P<0.01)$. Specific angioarchitectonic features such as venous stenoses, varicose dilatation of the draining vein, arterial aneurysms of the feeding artery, arteriovenous fistula within the nidus, contralateral drainage and sinushypo/-aplasia did not alter the bleeding rate.

Interpretation. Various angiographic features were correlated with the occurrance of intracranial haemorrhage in patients with cerebral AVMs. In addition to the well-known factors influencing the bleeding risk of cAVMs like size, pattern of venous drainage and location within the brain our data demonstrate the importance to look at the diameter of the main feeder and the number of draining veins showing a better correlation.

\section{Introduction}

Cerebral AVMs (cAVMs) are generally regarded as congenital vascular lesions resulting from a disorder of embryonic vascular morphogenesis caused by a defect or malfunction of the embryonic capillary maturation process leading to the formation of an arteriovenous shunt [10]. In general a cAVM consists of a feeding artery, one or more mostly dilated draining veins and a centrally located nidus. The nidus itself is a conglomerate of atypical vessels of variable diameter and wall thickness, which does not contain normal capillaries $[17,18]$. In a series of 166 prospectively followed unoperated symptomatic patients with cerebral AVMs with a mean follow-up period of 23.7 years the mortality rate was $1 \%$ per year and the rate of a major rebleed was $4 \%$ per year [23]. However the natural history of an untreated cerebral AVM is difficult to assess precisely and would require prospective studies explaining the controversial discussion in the literature $[3,4,7,8,13$, 23, 26, 34]. The incidence of intracerebral haemorrhage associated with angioarchitectonic parameters of AVMs has been the subject of several reports, partially presenting conflicting data $[3,4,7,13,14,34]$. The reason being perhaps the difficult and subjective analysis, the often only small numbers being examined and the unknown haemodynamic changes of an AVM over time and having undergone haemorrhage. The purpose of our study was therefore to determine further parameters of angioarchitecture being more powerful to predict an increased risk of intracranial haemorrhage.

\section{Patients and methods}

171 patients, the age ranging from 8 to 67 years with an average of 38 years, treated in our department were retrospectively analysed. The mean age was 36.5 years in men and 36.4 years in women with a sex 
ratio of male: female of 1.19:1. Out of 171 patients, 94 were admitted to hospital due to intracranial haemorrhage including intracerebral bleeding in 59, subarachnoid haemorrhage in 16 and a combination of intracranial haemorrhage and subarachnoid haemorrhage in 18, one patient presented with a subdural haematoma. Upon admission, 136 patients had neurological deficits which depended on the site of haemorrhage, the location of the AVM or were the result of seizures. The other 35 patients had no neurological deficits.

Cranial CT scans and/or MR images were carried out in all patients. Digital subtraction angiography was performed in all patients via a transfemoral approach. In most patients superselective angiography was carried out using a co-axial microcatheter technique.

The exact localisation of the cAVMs were derived from the combined evaluation of the angiographic series, cranial CT scans and MR images. The size of the AVM was assessed as the maximal diameter of the nidus on the angiographic views. The AVMs were categorized in 5 groups, i.e. micro $(0.5<1 \mathrm{~cm})$, small $(1<2 \mathrm{~cm})$, middle $(2<4 \mathrm{~cm})$, large $(4<6 \mathrm{~cm})$ and giant AVMs $(>6 \mathrm{~cm})$.

For the determination of the diameter of the feeding artery the mean was calculated from measurements taken at the origin, middle and terminal portion of the vessel on angiograms.

The haemodynamics of the cAVMs were classified into low, middle or high flow. A cAVM was considered to be of low flow if there was an early draining vein with no further change in haemodynamics. A middleflow cAVM was characterised by early venous drainage and an entirely contrasted nidus before the appareance of regularly draining cerebral veins. High-flow AVMs presented as a reduced filling of cerebral arteries at the time of a completely contrasted nidus.

As special morphological features of cerebral AVMs aneurysms of the arterial feeder, varicose dilatations of the draining vein, arteriovenous fistulas within the nidus, venous stenoses, contralateral drainage and sinushypo/-aplasia were evaluated and correlated with the incidence of bleeding (Table 8).

A $\chi^{2}$ test was conducted for the statistical analysis of the data.

\section{Results}

\section{Angioarchitecture of Cerebral AVMs}

Localisation

Most AVMs were located in the temporal $(\mathrm{n}=27 /$ $15.8 \%)$ and frontal $(\mathrm{n}=26 / 15.2 \%)$ lobes (Table 1). The correlation of bleeding risk versus the localisation of the cAVM showed an increased bleeding risk for deeply and infratentorially located AVMs, such as the basal ganglia/thalamus (12 out of 16 had bled, $75 \%$ ), corpus callosum ( 8 out of 8 had bled, 100\%), hippocam-
Table 1. Localisation of the AVMs

\begin{tabular}{lcc}
\hline Localisation & Number of patients & Percentage \\
\hline Frontal & 26 & 15.2 \\
Frontoparietal & 16 & 9.4 \\
Frontotemporal & 8 & 4.7 \\
Temporal & 27 & 15.8 \\
Temporoparietal & 8 & 4.7 \\
Temporooccipital & 3 & 1.8 \\
Occipital & 17 & 9.9 \\
Parietooccipital & 9 & 5.3 \\
Parietal & 16 & 9.4 \\
Thalamus & 10 & 5.8 \\
Thalamus and Ncl. lentiformis & 6 & 3.5 \\
Corpus callosum & 8 & 4.7 \\
Hippocampus & 3 & 1.8 \\
Cerebellar hemisphere & 10 & 5.8 \\
Vermis & 3 & 1.8 \\
Hypothalamic & 1 & 0.6 \\
Total & 171 & 100 \\
\hline
\end{tabular}

pus ( 2 out of 3 had bled, 67\%) or cerebellum (12 out of 13 had bled, 92\%).

Size

According to their maximal diameters, cerebral AVMs were classified into five groups. $16(9.4 \%)$ AVMs were microangiomas $(0.5 \leq 1 \mathrm{~cm}), 27(15.8 \%)$ were small AVMs $(1 \leq 2 \mathrm{~cm}), 88(51.5 \%)$ were middle sized AVMs $(2 \leq 4 \mathrm{~cm}), 29(17.0 \%)$ were large $(4 \leq 6 \mathrm{~cm})$ and 11 (6.4\%) were giant AVMs $(>6 \mathrm{~cm})$. Small and microangiomas had a much higher bleeding risk $(35 / 43$, $P<0.001$ ) than larger ones (Table 2). 57 of the 117 middle sized and large AVMs had bled (48.7\%), however 9 out of 11 giant AVMs suffered no bleeding (81.8\%). No correlation could be found between the size of the AVM and the diameter of its feeding artery or its draining vein.

\section{Arterial supply}

Out of the 171 AVMs $51(29.8 \%)$ were supplied by one or two arteries, 52 AVMs (30.4\%) by three or four

Table 2. Incidence of haemorrhage depending on the size (max. diameter) of the nidus

\begin{tabular}{|c|c|c|c|c|}
\hline Size of the nidus & Haemorrhage & No haemorrhage & Total & $p$-value \\
\hline Microangiomas $(0.5 \leq 1 \mathrm{~cm})$ & 13 & 3 & $16(9.4 \%)$ & $p<0.001$ \\
\hline Small AVMs $(1 \leq 2 \mathrm{~cm})$ & 22 & 5 & $27(15.8 \%)$ & $p<0.001$ \\
\hline Middle sized AVMs $(2 \leq 4 \mathrm{~cm})$ & 42 & 46 & $88(51.5 \%)$ & \\
\hline Large AVMs $(4 \leq 6 \mathrm{~cm})$ & 15 & 14 & $29(17.0 \%)$ & \\
\hline Giant AVMs $(>6 \mathrm{~cm})$ & 2 & 9 & $11(6.4 \%)$ & \\
\hline Total & $94(55.0 \%)$ & $77(45.0 \%)$ & $171(100 \%)$ & \\
\hline
\end{tabular}


arteries and 68 AVMs (39.8\%) by five or more arteries, the highest being 18 arteries. AVMs with 2 or less feeding arteries had a significantly higher incidence of bleeding, i.e. 17 out of 34 had bled $(P<0.001$, Table 3).

In addition to the number of arterial feeders the diameter of the main feeder proved itself to be a highly important criterion. The mean diameter of the feeding arteries varied between 0.5 to $3.5 \mathrm{~mm}$, one measuring $4 \mathrm{~mm}$. 93 out of 171 AVMs (54.4\%) had feeding arteries with a diameter between 1.1 and $2.0 \mathrm{~mm}$, whereas 28 out of $171(16.4 \%)$ lay between 0.5 and $1.0 \mathrm{~mm}$ and 49 out of 171 (28.7\%) between 2.0 and $3.5 \mathrm{~mm}$. There was a significantly increased bleeding risk for AVMs with feeding arteries less or equal to $1.0 \mathrm{~mm}$ of diameter. 26 out of 28 cerebral arteriovenous malformations $(93 \%)$ had bled $(P<0.0001$, Table 4).

Venous drainage

90 out of 171 cerebral AVMs (52.6\%) were drained by superficial veins, whereas 22 AVMs (12.9\%) showed a drainage by deep veins and 59 AVMs (35.5\%) by both. Out of the 22 AVMs drained by deep veins 18 (81.8\%) had bled $(P<0.05)$. However AVMs with a predominantly superficial or mixed venous drainage showed no increased bleeding risk (Table 5).

The number of draining veins varied between one and nine for the cortical veins and between one and three for the deep veins and showed a correlation with the size of the AVMs. AVMs with a diameter of more than $4 \mathrm{~cm}$ had a higher number of draining veins, whereas about $80 \%$ of the AVMs up to $2 \mathrm{~cm}$ had no more than 2 draining veins. For these AVMs with only one or two draining veins a highly significant increase of intracranial bleeding was found $(P<0.001)$. Out of 77 AVMs with two or less draining veins 55 (71.4\%) had bled (Table 6).

\section{Haemodynamics}

According to their haemodynamic characteristics on angiograms, cerebral AVMs were divided into lowflow, mid-flow and high-flow AVMs. Most cerebral AVMs $(133 / 171,77.8 \%)$ were high-flow lesions,

Table 3. Correlation between the number of arterial feeders and the incidence of haemorrhage

\begin{tabular}{lllll}
\hline Number of arterial feeders & Haemorrhage & No haemorrhage & Total & $p$-value \\
\hline$\leq 2$ Feeders & 34 & 17 & $51(29.8 \%)$ & $p<0.001$ \\
3-4 Feeders & 29 & 23 & $52(30.4 \%)$ & $68(39.8 \%)$ \\
$\geq 5$ Feeders & 31 & 37 & $171(100 \%)$ \\
Total & $94(55.0 \%)$ & $77(45.0 \%)$ & \\
\hline
\end{tabular}

Table 4. Correlation between the diameter of the feeding artery and the incidence of haemorrhage

\begin{tabular}{llccc}
\hline Diameter & Haemorrhage & No haemorrhage & Total & $p$-value \\
\hline $0.5-1.0 \mathrm{~mm}$ & 26 & 2 & $28(16.4 \%)$ & $p<0.0001$ \\
$1.1-2.0 \mathrm{~mm}$ & 53 & 40 & $93(54.4 \%)$ & $49(28.7 \%)$ \\
$2.1-3.5 \mathrm{~mm}$ & 15 & 34 & $1(0.6 \%)$ \\
$>3.5 \mathrm{~mm}$ & 0 & 1 & $171(100 \%)$ \\
Total & $94(55.0 \%)$ & $77(45.0 \%)$ & & \\
\hline
\end{tabular}

Table 5. Incidence of haemorrhage depending on the drainage

\begin{tabular}{|c|c|c|c|c|}
\hline & Haemorrhage & No haemorrhage & Total & $p$-value \\
\hline Superficial drainage & $44(48.9 \%)$ & $46(51.1 \%)$ & $90(52.6 \%)$ & \multirow{4}{*}{$p<0.05$} \\
\hline Deep drainage & $18(81.8 \%)$ & $4(18.2 \%)$ & $22(12.9 \%)$ & \\
\hline Mixed drainage & $32(54.2 \%)$ & $27(45.8 \%)$ & $59(34.5 \%)$ & \\
\hline Total & $94(55.0 \%)$ & $77(45.5 \%)$ & $171(100 \%)$ & \\
\hline
\end{tabular}


Table 6. Incidence of haemorrhage depending on the number of draining veins

\begin{tabular}{|c|c|c|c|c|}
\hline Number of draining veins & Haemorrhage & No haemorrhage & Total & $p$-value \\
\hline 1-2 Veins & $55(71.4 \%)$ & $22(28.6 \%)$ & $77(45.0 \%)$ & \multirow[t]{4}{*}{$p<0.001$} \\
\hline 3-4 Veins & $21(40.4 \%)$ & $31(59.6 \%)$ & $52(30.4 \%)$ & \\
\hline 5-9 Veins & $18(42.9 \%)$ & $24(57.1 \%)$ & $42(24.6 \%)$ & \\
\hline Total & $94(45.0 \%)$ & $77(55.0 \%)$ & $171(100 \%)$ & \\
\hline
\end{tabular}

Table 7. Correlation between the incidence of haemorrhage and the flow-velocity

\begin{tabular}{lcccc}
\hline Flow-Velocity & Haemorrhage & No haemorrhage & Total & $p$-value \\
\hline High-flow & $65(48.9 \%)$ & $68(51.1 \%)$ & $133(77.8 \%)$ & \\
Middle-flow & $24(72.7 \%)$ & $9(27.3 \%)$ & $33(19.3 \%)$ & \\
Low-flow & $5(100 \%)$ & 0 & $5(2.9 \%)$ & $p<0.01$ \\
Total & $94(55.0 \%)$ & $77(45.0 \%)$ & $171(100 \%)$ & \\
\hline
\end{tabular}

whereas $33(19.3 \%)$ were mid-flow and only $5(2.9 \%)$ were low-flow lesions. The correlation between the flow velocity and the incidence of bleeding revealed that all low-flow AVMs (5/5) and the majority (24/33) of mid-flow AVMs had bled. On the contrary, there was no significant increase of bleeding in highflow AVMs $(P<0.01$, Table 7). The low-flow AVMs were less or equal to $2 \mathrm{~cm}$ in size, whereas the midflow AVMs ranged from $5 \mathrm{~mm}$ to $41 \mathrm{~mm}$, about $75 \%$ lying between $2-4 \mathrm{~cm}$.

\section{Specific angioarchitecture}

21 out of 171 patients (12.3\%) showed an arterial aneurysm of the feeding artery (Fig. 1) and two patients showed two arterial aneurysms. 13 out of these 23 patients $(56.5 \%)$ had bled reaching no statistical significance (Table 8). All these aneurysms were located at the feeding arteries close to the nidus and differed greatly in size.

Varicose dilatation of the draining vessel was found in 57 AVMs (33.3\%), out of which 24 (42.1\%) had bled
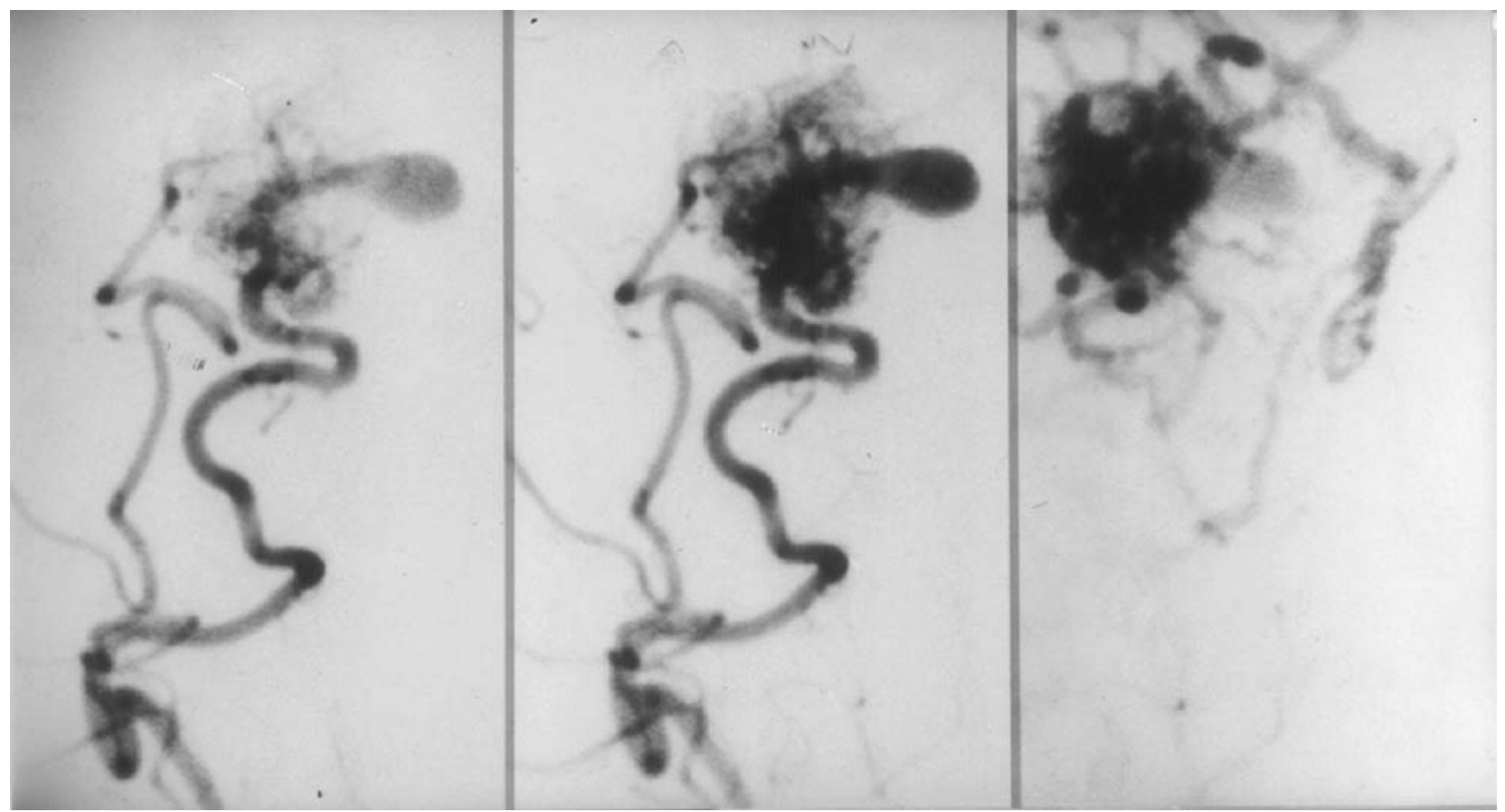

Fig. 1. Supraselective angiography of a parietal arteriovenous malformation with a saccular aneurysm 
Table 8. Incidence of haemorrhage depending on certain morphological features

\begin{tabular}{lcc}
\hline Angioarchitecture & $\begin{array}{l}\text { Presence of the morphological } \\
\text { feature }(\mathrm{n}=171)\end{array}$ & $\begin{array}{l}\text { Incidence of haemorrhage } \\
\text { within its group }\end{array}$ \\
\hline Aneurysms & $23(13.5 \%)$ & $13(56.5 \%)$ \\
Art.-ven. fistulas & $101(59.1 \%)$ & $50(49.5 \%)$ \\
Steal-effects & $75(43.9 \%)$ & $32(42.7 \%)$ \\
Varicose dilatation & $57(33.3 \%)$ & $24(42.1 \%)$ \\
Venous stenosis & $67(39.2 \%)$ & $35(52.2 \%)$ \\
Contralateral drainage & $20(11.7 \%)$ & $11(55.0 \%)$ \\
Sinushypo/-aplasia & $6(3.5 \%)$ & $4(66.7 \%)$ \\
\hline
\end{tabular}

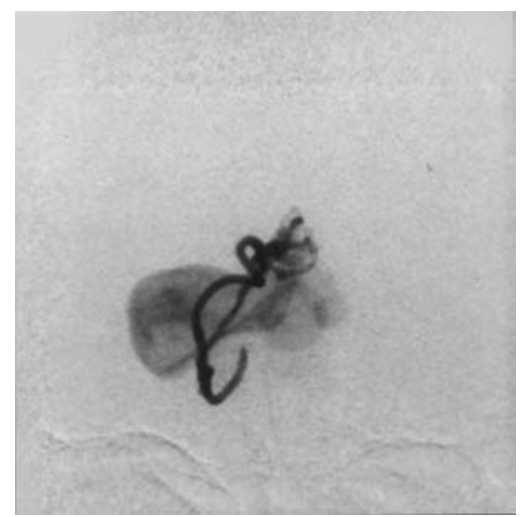

Fig. 2. Varicose dilatation of an arteriovenous malformation of the posterior choroidal artery

(Table 8, Fig. 2), showing a tendency towards a reduction of the bleeding risk.

A stenosis of the draining vein was found in 67 cases (39.2\%). The stenosis could be located anywhere along the vessel, but the majority lay at the proximal portion of the draining vessel. In some cases the stenosis was found at the entrance of veins into the sinus, esp. at the Galenic point (Fig. 3). The number of stenotic draining veins per AVMs varied between one and four. 55 AVMs had only one venous stenosis, whereas nine AVMs had two, two

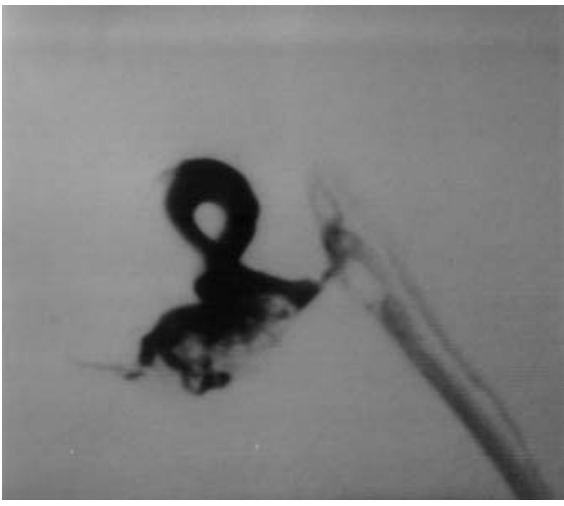

Fig. 3. Lateral view of a deeply located arteriovenous malformation demonstrating a stenosis of the draining vein at the Galenic point

AVMs had three and one AVM had four stenosis. However, the relationship between the number of venous stenosis and the incidence of bleeding did not reveal any statistically significant change of bleeding risk. The distance of the stenosis from the nidus and the incidence of bleeding was not statistically significant either.

In 101 cases $(59.1 \%)$ fistulae were demonstrated within the nidus, although neither an increased nor a lowered bleeding risk related to the fistula could be found (Fig. 4).

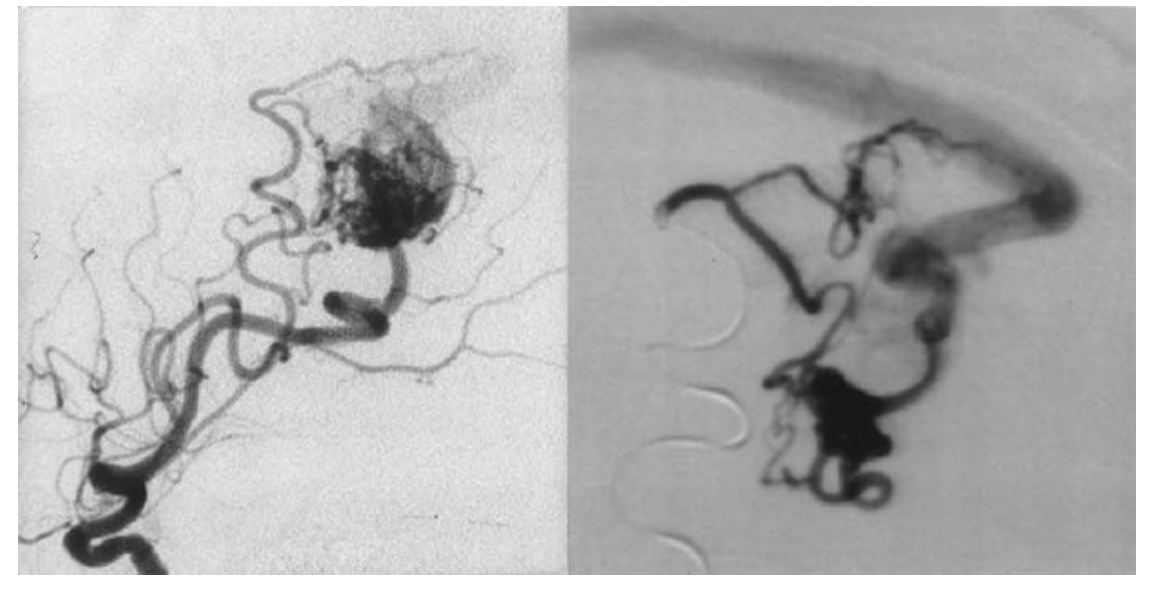

Fig. 4. Left: Angiogram of left internal carotid artery lateral view with a temporoparietal arteriovenous malformation. Right: Supraselective angiography demonstrating the angioarchitecture with intranidal fistulas and early drainage into cortical veins 
The evaluation of contralateral drainage of the cAVM present in 20 cases (11.7\%) as well as a sinushypo/ -aplasia present in 6 cases $(3.5 \%)$ did not alter the risk for intracranial haemorrhage (Table 8). However for sinushypoplasia or sinusaplasia this may only be due to small numbers since 4 out of 6 AVMs bled suggesting a tendancy towards an increased bleeding risk.

\section{Discussion}

The standard categorisation of arteriovenous malformations from a surgical point of view involves the Spetzler-Martin grading system [28], which uses a simple analysis of size, location and venous drainage. For the risk of intracranial haemorrhage the location of the cAVM seems to play a dominant role. In the recent literature Turjman et al. [31] showed a higher incidence of bleeding, when the AVM was located in the basal ganglia and Mansmann found a correlation with AVMs in the corticocallosal and posterior fossa location [13]. In our study out of $16 \mathrm{AVMs}$ in the basal ganglia 12 (75\%) had caused intracranial haemorrhage supporting these findings and moreover an increased rate of haemorrhage could be shown for all AVMs located deeply or infratentorially, i.e. AVMs of the basal ganglia, corpus callosum, hippocampus and cerebellum. Besides the localisation other responsible factors for this increase of associated bleeding may include the presence of additional risk factors, such as stenosis of the vein of Galen or short feeding arteries with high pressure in these deeply located AVMs.

The classification of cAVMs according to their sizes varies in the literature [28, 31]. In our study we choose the category of $>6 \mathrm{~cm}$ following the Spetzler - Martin grading system, the other AVMs were placed in 4 subgrous (i.e. micro, small, middle, large) instead of 2 subgroups $(<3 \mathrm{~cm}, 3-6 \mathrm{~cm})$ to obtain a more accurate discrimination concerning the risk of haemorrhage. About $50 \%$ of the AVMs belonged to the middle-sized group, whereas $25 \%$ belonged to either the smaller or the larger groups. Within the two groups of micro and small AVMs a significantly increased bleeding risk was found compared to middle, large and giant AVMs. Out of the 43 AVMs with small volumes 35 (81.4\%) had bled $(P<0.001)$. Giant AVMs with a maximal diameter of more than $6 \mathrm{~cm}$ showed a significantly decreased incidence of bleeding. These results are in accordance with the findings in the literature $[1,4,9,10,12,24,25,27$, 29] and, keeping in mind the limitations of a retrospective analysis not representing the natural history of
AVMs, it can be assumed that the 171 patients in our study give a representative picture of symptomatic cAVMs.

Looking at the number of arterial feeders we found a highly significant correlation: AVMs with more than five feeding arteries had a lower bleeding risk and those with maximally two arterial feeders had a higher bleeding risk $(P<0.001)$. This result could be due to a correlation between the size of the nidus and the number of arterial feeders, since two-thirds of the AVMs less than $2 \mathrm{~cm}$ in diameter were supplied by only one or two feeding arteries.

AVMs with a feeding artery of maximal $1.0 \mathrm{~mm}$ of vessel diameter showed a markedly increased bleeding risk $(P<0.0001)$. To our knowledge this parameter has not been looked at in the past, however its consideration could play a major role for the estimation of the risk of haemorrhage and should be investigated more thoroughly in a prospective trial. A potential explanation for this phenomenon could be the decline of pressure within the feeder which increases with a smaller diameter, which is consistent with the law of HagenPoiseuille.

Impairment of the venous drainage has previously been described to play a major role for an increased rate of haemorrhage [7, 9, 23]. In our study we found that 55 out of 77 cAVMs (71.4\%) with up to two draining veins had bled $(p<0.001)$. In contrast Vinuela [33] did not confirm this correlation between the number of draining veins and the incidence of bleeding, however our data are in agreement with the findings by Albert [1] in 150 patients. On the other hand cerebral AVMs with five or more draining veins showed a lower bleeding risk. The reason could be a better outflow of the blood from the nidus correlating with a lower intranidal pressure. In contrast in case of a limited draining system, possibly the pressure within the nidus and its feeding and draining vessels rises and vessel rupture may result. This hypothesis is supported by the findings of Nornes and Grip [22], who reported that the mean venous pressure in the nidus region is $17 \mathrm{mmHg}$ in patients with an AVM with bleeding and $14 \mathrm{mmHg}$ in patients with an AVM without bleeding and by Spetzler et al. [29], who measured the vascular pressure intra-operatively. We assume therefore that the intravascular pressure within the nidus and its related veins is a decisive factor concerning the bleeding risk.

The relevance of superficial or deep venous drainage of cerebral AVMs has been examined in several studies $[5,13,15,20,31,33]$ and has been regarded as an 
important risk issue. Our data stress further the major role of this risk factor, since 18 out of 22 AVMs (81.8\%) with pure deep venous drainage had bled, whereas AVMs with superficial or mixed drainage showed no increased incidence of bleeding.

In this study venous stenoses were demonstrated in 67 AVMs (39.2\%) both in the cortical and deep draining veins. Stenosis in deep cerebral veins was most frequently located in the vein of Galen. Vinuela [33] studied 53 deep brain AVMs and found a stenosis in the vein of Galen in 14 AVMs and occlusion in the inner draining system in 7 AVMs. Their formation could be based upon the anatomical particularity of this draining system. The venous blood from the deep white substance, basal ganglia, corpus callosum, third and fourth ventricles gathers in the region of the Galenic system and drains into only one vein. This causes marked haemodynamic changes including a change from laminary to turbulent blood flow, which can cause endothelial injury and subsequent thrombotic occlusion or vessel stenosis [6]. By intra-operative Doppler sonography Nornes and Grip [22] showed, that a turbulent flow and an increased intravascular pressure could produce shearing stress with endothelial destruction and, consecutively, a secondary thrombosis. The degree of stenosis in the present study varied between $20 \%$ and $90 \%$. Four out of 5 AVMs with more than $80 \%$ stenosis of a draining vein presented with intracranial haemorrhage. This increased incidence of bleeding is in agreement with previous studies and is presumably due to proximal venous hypertension. In our patients most stenoses lay 3 to $4 \mathrm{~cm}$ distal to the nidus and there was no poststenotic dilation in the cortical draining veins. However, Albert [1] considered venous stenosis an anatomical variation or due to angiographic projection.

In the present study contrary to venous stenosis an ectatic dilatation of a draining vein showed a tendency towards a lower bleeding risk but did not reach statistical significance. This finding is discussed controversially in the literature. Nataf et al. [21] found a weak positive correlation of venous ectasia and a higher incidence of bleeding, whereas Mansmann [13] described a lower rate of ICH. However, our results are in good agreement with the findings of Turjman et al. [31], who did not find any correlation. The cause for these discrepancies could lie in the missing detailed analysis in how many cases the venous ectasia was associated with an adjacent stenosis. Valavanis et al. [32] describe a varix formation proximal to a high-grade stenosis of draining veins being a predisposing factor of AVM rupture. Therefore in combination with a stenosis the risk for haemorrhage may increase, whereas a venous dilatation by itself may well be associated with a lower bleeding risk, since it may act as a buffer zone.

The association of arterial aneurysms with cerebral AVMs has been widely studied. The reported incidence of such aneurysms varies greatly from $2.7 \%$ to $23 \%$ with an average of about $10 \%$ [2, 11, 19, 26, 35, 36]. In recent studies using superselective angiography, Turjman [30] found the incidence of such aneurysms being as high as $58 \%$. In our study arterial aneurysms in the feeding artery were found in 23 AVMs (13.5\%), the lower prevalence being possibly explained by the fact, that not all of our diagnostic angiographies were performed superselectively. However, the finding of a tendancy towards an increased risk for haemorrhage with $57 \%$ of these AVMs having bled is in good agreement with the literature $[2,14,16,35]$.

In 101 AVMs (59.1\%) arteriovenous fistulas were found in the nidus out of which 50 (49.5\%) had bled. An increased risk of haemorrhage could not be demonstrated in these AVMs, which is in agreement with Willinsky et al., who reported a $40 \%$ incidence of bleeding in AVMs with this characteristic [35].

Another aspect studied in our patients was the correlation of flow-velocity and bleeding risk. 133 AVMs (77.8\%) were high-flow, 33 (19.3\%) were mid-flow and $5(2.9 \%)$ were low-flow AVMs. Lesions with highflow had no increased incidence of bleeding. On the contrary, all low-flow and 29 of the 38 mid-flow AVMs (76.3\%) had bled. A possible explanation is the higher intravascular pressure due to the delayed venous blood drainage as well as the fact, that low flow-velocities were only present in small and micro AVMs and middle flow-velocities mainly in small and middle AVMs and these have per se a higher tendency to bleed.

\section{References}

1. Albert P, Salgado H, Polaina M, Trujillo F, Ponce de Leon A, Durand F (1990) A study on the venous drainage of 150 cerebral arteriovenous malformations as related to hemorrhagic risks and size of the lesions. Acta Neurochir (Wien) 103: 30-34

2. Batjer H, Suss RA, Samson D (1986) Intracranial arteriovenous malformations associated with aneurysms. Neurosurgery 18: 29-35

3. Brown RD Jr, Wiebers DO, Forbes G, O'Fallon WM, Piepgras DG, Marsh WR, Maciunas RJ (1988) The natural history of unruptured intracranial arteriovenous malformations. J Neurosurg 68: 352-357

4. Crawford PM, West CR, Chadwick DW, Shaw MD (1986) Arteriovenous malformations of the brain: natural history in unoperated patients. J Neurol Neurosurg Psychiatry 49: 1-10 
5. Dobbelaere P, Jomin M, Clarisse J, Laine E (1979) Prognostic importance of the study of venous drainage in cerebral arteriovenous aneurysms [in French]. Neurochirurgie 25: 178-184

6. Fry DL (1968) Acute vascular endothelial changes associated with increased blood velocity gradients. Circ Res 22: 165-197

7. Graf CJ, Perret GE, Torner JC (1983) Bleeding from cerebral arteriovenous malformations as part of their natural history. J Neurosurg 58: 331-337

8. Graves VB, Duff TA (1990) Intracranial arteriovenous malformations. Current imaging and treatment. Invest Radiol 25: 952-960

9. Guidetti B, Delitala A (1980) Intracranial arteriovenous malformations: conservative and surgical treatment. J Neurosurg 53: $149-152$

10. Kaplan HA, Aronson StM, Browder EJ (1961) Vascular malformations of the brain: an anatomical study. J Neurosurg 18: 630-635

11. Lasjaunias P, Piske R, Terbrugge K, Willinsky R (1988) Cerebral arteriovenous malformations (C. AVM) and associated arterial aneurysms (AA). Analysis of $101 \mathrm{C}$. AVM cases, with 37 AA in 23 patients. Acta Neurochir (Wien) 91: 29-36

12. Luessenhop AJ, Rosa L (1984) Cerebral arteriovenous malformations. Indications for and results of surgery, and the role of intravascular techniques. J Neurosurg 60: 14-22

13. Mansmann U, Meisel J, Brock M, Rodesch G, Alvarez H, Lasjaunias P (2000) Factors Associated with Intracranial Hemorrhage in Cases of Cerebral Arteriovenous Malformation. Neurosurgery $46: 272-281$

14. Marks MP, Lane B, Steinberg GK, Chang PJ (1990) Hemorrhage in intracerebral arteriovenous malformations: angiographic determinants. Radiology 176: 807-813

15. Marks MP, Lane B, Steinberg G, Chang P (1991) Vascular characteristics of intracerebral arteriovenous malformations in patients with clinical steal. AJNR Am J Neuroradiol 12: 489-496

16. Marks MP, Lane B, Steinberg GK, Snipes GJ (1992) Intranidal aneurysms in cerebral arteriovenous malformations: evaluation and endovascular treatment. Radiology 183: 355-360

17. Massoud TF, Ji C, Vinuela F, Guglielmi G, Robert J, Duckwiler GR, Gobin YP (1994) An experimental arteriovenous malformation model in swine: anatomic basis and construction technique. AJNR Am J Neuroradiol 15: 1537-1545

18. Massoud TF, Ji C, Guglielmi G, Vinuela F (1996) Endovascular treatment of arteriovenous malformations with selective intranidal occlusion by detachable platinum electrodes: technical feasibility in a swine mode. AJNR Am J Neuroradiol 17: 1459-1466

19. Müller-Forell W, Valvanis A (1991) Neuroradiologic exploration of cerebral arteriovenous malformations [in German]. Radiologe 31: 269-273

20. Miyasaka Y, Yada K, Ohwada T, Kitahara T, Kurata A, Irikura K (1992) An analysis of the venous drainage system as a factor in hemorrhage from arteriovenous malformations. J Neurosurg 76: 239-243

21. Nataf F, Meder JF, Roux FX, Blustajn J, Merienne L, Merland JJ, Schlienger M, Chodkiewicz JP (1997) Angioarchitecture associated with haemorrhage in cerebral arteriovenous malformations: a prognostic statistical model. Neuroradiology 39: 52-58

22. Nornes H, Grip A (1980) Hemodynamic aspects of cerebral arteriovenous malformations. J Neurosurg 53: 456-464

23. Ondra SL, Troupp H, George ED, Schwab K (1990) The natural history of symptomatic arteriovenous malformations of the brain: a 24-year follow-up assessment. J Neurosurg 73: 387-391

24. Parkinson D, Bachers G (1980) Arteriovenous malformations. Summary of 100 consecutive supratentorial cases. J Neurosurg 53: 285-299

25. Pellettieri L, Carlsson CA, Grevsten S, Norlen G, Uhlemann C (1979) Surgical versus conservative treatment of intracranial arte- riovenous malformations: a study in surgical decision-making. Acta Neurochir (Wien) [Suppl] 29: 1-86

26. Perret G, Nishioka H (1966) Report on the cooperative study of intracranial aneurysms and subarachnoidal hemorrhage. Section VI: Arteriovenous malformations: An analysis of 545 cases of cranial-cerebral arteriovenous malformations and fistulae reported to the cooperative study. J Neurosurg 25: 467-490

27. Shi YQ, Chen XC (1986) A proposed scheme for grading intracranial arteriovenous malformations. J Neurosurg 65: 484-489

28. Spetzler RF, Martin NA (1986) A proposed grading system for arteriovenous malformations. J Neurosurg 65: 476-483

29. Spetzler RF, Hargraves RW, McCormick PW, Zabramski JM, Flom RA, Zimmerman RS (1992) Relationship of perfusion pressure and size to risk of hemorrhage from arteriovenous malformations. J Neurosurg 76: 918-923

30. Turjman F, Massoud TF, Vinuela F, Sayre JW, Guglielmi G, Duckwiler G (1994) Aneurysms related to cerebral arteriovenous malformations: superselective angiographic assessment in 58 patients. AJNR Am J Neuroradiol 15: 1601-1605

31. Turjman F, Massoud TF, Vinuela F, Sayre JW, Guglielmi G, Duckwiler G (1995) Correlation of the angioarchitectural features of cerebral arteriovenous malformations with clinical presentation of hemorrhage. Neurosurgery $37: 856-862$

32. Valavanis A, Yasargil MG (1998) The endovascular treatment of brain arteriovenous malformations. Adv Tech Stand Neurosurg 24: $131-214$

33. Vinuela F, Nombela L, Roach MR, Fox AJ, Pelz DM (1985) Stenotic and occlusive disease of the venous drainage system of deep brain AVM's. J Neurosurg 63: 180-184

34. Wilkins RH (1985) Natural history of intracranial vascular malformations: a review. Neurosurgery 16: 421-430

35. Willinsky R, Lasjaunias P, Terbrugge K, Pruvost P (1988) Brain arteriovenous malformations: Analysis of the angio-architecture in relationship to hemorrhage (based on 152 patients explored and/or treated at the hospital de Bicetre between 1981 and 1986). J Neuroradiol 15: 225-237 